

\title{
Interface-dominant multilayers fabricated by severe plastic deformation: Stability under extreme conditions
}

\author{
Nathan A. Mara, ${ }^{1,2 *}$ Irene J. Beyerlein ${ }^{3}$ \\ ${ }^{1}$ Institute for Materials Science, Los Alamos National Laboratory \\ ${ }^{2}$ Center for Integrated Nanotechnologies, Los Alamos National Laboratory \\ ${ }^{3}$ Theoretical Division, Los Alamos National Laboratory \\ *corresponding author: namara@lanl.gov; 505-667-8665 \\ PO Box 1663, Los Alamos, New Mexico, 87545 USA
}

\begin{abstract}
Over the past 3-5 years, the ability to process interface dominant nanolayered bimetallic composites in bulk quantities has opened new opportunities for investigations into structural material behavior under extreme strains. This article reviews the emergence of mechanically stable, predominant bimetallic interface characters during nanomaterial synthesis via Accumulative Roll Bonding, a severe plastic deformation technique. This processing method itself imposes an extreme condition. We show that the interfaces that are naturally selected by this extreme operation remarkably prove to be stable under exposure to other extreme conditions, including elevated temperatures and ion irradiation. Through control of synthesis pathways, interfaces of the desired atomic structure can be manufactured using scalable thermomechanical processing techniques. This, in turn, opens unprecedented new possibilities for designing bulk materials with interface-dominant properties including enhanced strength, deformability, thermal stability, and radiation damage tolerance.
\end{abstract}

\section{Keywords:}

Nanocomposite; Mechanical behavior; radiation damage tolerance; elevated temperature stability; deformation twinning; bimetal interface; severe plastic deformation; texture; crystal plasticity; dislocations 


\subsection{Stability of Metallic Materials Under Extreme Strains}

Extreme or severe mechanical strains (in excess of Von Mises strains of 1) push metals far from equilibrium and cause the microstructure to undergo many substantial changes. Most metals studied in this extreme are usually polycrystals, comprised of many grains of different crystallographic orientation. To accommodate the strain, the crystals in polycrystalline metals distort by plastic slip on particular slip systems to achieve more energetically favorable orientations[1] while being under the constraint of the neighboring crystals[1-3]. At the same time, the intervening network of grain boundaries and interfaces evolve with strain to other misorientations and crystallographic characters[4]. Most grain boundaries accumulate stored dislocations and consequently become disordered at the nano- and atomic-level[5-7]. New grain boundaries are created and the average grain size becomes smaller, increasing the overall boundary content of the microstructure.

The grain refinement caused by SPD leads to greatly improved strength. However, the strength and the plastically strained microstructure are lost when the material is subsequently exposed to extreme conditions that differ from that used to create it. For instance, when ultra-fine-grained (UFG) $\mathrm{Cu}$ produced by severe plastic deformation is subjected to moderately enhanced temperatures, the grains grow $[8,9]$. When exposed to light-ion irradiation, grain boundaries in UFG $\mathrm{Cu}$ are susceptible to void formation[10]. These results are common to pure UFG metals and it is well accepted that a microstructure that has stabilized under extreme mechanical strains would not necessarily be stable in another extreme condition.

In this respect, experimental reports indicate that bimetal interfaces could be different from grain boundaries. At first, such findings were outcomes of fundamental studies made on model-like two-phase nanolayered thin film samples prepared by electrodeposition or physical vapor deposition [11-16]. With these fabrication methods, the individual layer thicknesses can be controlled at the 2 to $5 \mathrm{~nm}$ range and the grains bounded by bimetal interfaces take on aspect ratios between 1-2. Accordingly, these nanolayered composites contain both a high density of bimetal interfaces and grain boundaries. Experimental characterization finds them to be 5 to 10 times stronger and over one order of magnitude harder than their coarse-grained constituents[15, 17, 18]. More importantly, when exposed to light-ion irradiation and/or high temperatures, they exhibited outstanding microstructural stability, unlike the nanocrystalline metals alone[19]. These extreme conditions are very different from the near-equilibrium conditions in which these films were made.

However, engineering application of such fine-layered samples in structural applications is severely limited since the fabrication rate for small quantities thicknesses $(<\mathrm{mm})$ is very slow ( days). As a promising alternative, researchers have applied SPD to make layered composites in bulk via a technique called accumulative roll bonding (ARB) [2022]. The ARB process uses an iterative sequence of cleaning, stacking, roll bonding, and cutting to create and refine a lamellar microstructure[23]. This technique has been 
applied to several different bimetal systems[21, 22, 24-27]. Related SPD techniques such as repeated stacking and forging have been used to make pattern welded steels for at least decades, and may have been used to form Wootz layered steel alloys as early as 300 BC. $[28,29]$

Recent investigations on the properties of ARB-fabricated nanolayered composites have focused on the $\mathrm{Cu}-\mathrm{Nb}$ system, which was used in many prior studies of PVD foils. For the SPD process, the $\mathrm{Cu}-\mathrm{Nb}$ system additionally offers the advantages of low solid solubility and resistance to mechanical mixing, as well as similar flow stresses for the two phases. These two characteristics result in excellent microstructural stability during ARB processing, facilitating production of continuously layered, fine-scale nanolaminate material[30, 31]. Studies uncovered that ARB made $\mathrm{Cu}-\mathrm{Nb}$ nanolayered sheets are radiation tolerant, shock resistant, thermally stable, hard, strong, and deformable. They do not develop voids under light-ion irradiation[10], they maintain their nanostructure under temperatures of half the melting point of $\mathrm{Cu}[32,33]$, and they are found to sustain stresses exceeding an order of magnitude over the strength of either $\mathrm{Cu}$ or $\mathrm{Nb}$ alone during deformation to large strains $(>25 \%)[34]$. Thus, it appears that although these materials were made in one extreme condition (strain), they can be stable in another significantly different extreme condition.

In this article, we review recent studies that link microstructural stability under one extreme (e.g., strain) to stability under other extreme conditions, such as high temperatures, ion irradiation, and elevated temperature straining. We define stability as a microstructure's resistance to change crystallographically, morphologically, and/or chemically when it encounters extreme conditions such as large strains, high temperature, or irradiation. Crystallographic stability can be defined relative to texture distributions as previously mentioned, or can refer to a strain-independent interface character, defined by the three parameters that describe orientation relationship (OR) and two that describe the interface plane (IP). Morphological and chemical stability relate to microstructural robustness in terms of grain size/shape/porosity/aspect ratio and the tendency to maintain a constant chemical composition in the constituent phases, respectively. Under severe plastic deformation (SPD), both polycrystalline single-phase materials or two-phase composites can undergo evolution towards a steady-state microstructure that saturates with further strain.

We hypothesize that the interfacial characters that evolve under the extreme straining in $\mathrm{ARB}$ processing tend to not only be plastically stable, but also to be low in formation energy. Since they are created in an environment that requires the microstructure to mitigate damage accumulation in the face of large deformation defect (dislocation) fluxes, the interfaces that evolve will also show an affinity to damage mitigation under irradiation-induced point defect fluxes. The goal of this article is to discuss how the bimetal interface structure in metallic nanolayered composites enables materials to be stable in multiple extreme environments, situations in which the single-phase UFG and nanostructured constituents would not be stable.

\subsection{Stable orientations and stable orientation relationships}


The ARB process is depicted in Fig. 1. Figure 1a shows that the initial ARB step consists of cleaning and wire brushing high-purity single-phase sheets of $\mathrm{Cu}$ and $\mathrm{Nb}$ followed by room temperature roll bonding at reductions in thickness of $50-60 \%$ per pass. The initial, cold roll-bonding step produces a sheet of copper-clad $\mathrm{Nb}$. The central $\mathrm{Nb}$ layer is twice as thick as the $\mathrm{Cu}$ cladding and after the initial bonding step, and so in subsequent steps, the $\mathrm{Cu}$ 'half layers' are bonded together yielding a material with layers of equal thickness in each phase. This procedure has two main benefits: 1) Since all interfaces are produced in the first bonding step, every interface encounters the same rolling strains. 2) Any oxides trapped at the $\mathrm{Cu}-\mathrm{Nb}$ interfaces during the initial bonding step are spread over large interfacial areas during subsequent processing steps, reducing the tendency for them to affect interfacial performance[35, 36].

Through iteration of these cleaning, stacking, bonding, and cutting steps, the number of layers increases exponentially and the layer thickness decreases. The sheet thicknesses remain nearly constant during processing (see Figure $1 \mathrm{~b}, \mathrm{c}$ ), enabling extreme strains to be imparted to the material while preserving the bulk material dimensions. These strains exceed those typically encountered during conventional rolling: for example, synthesis of $15 \mathrm{~nm} \mathrm{Cu}-\mathrm{Nb}$ nanolaminates requires a rolling strain of 11.8 .
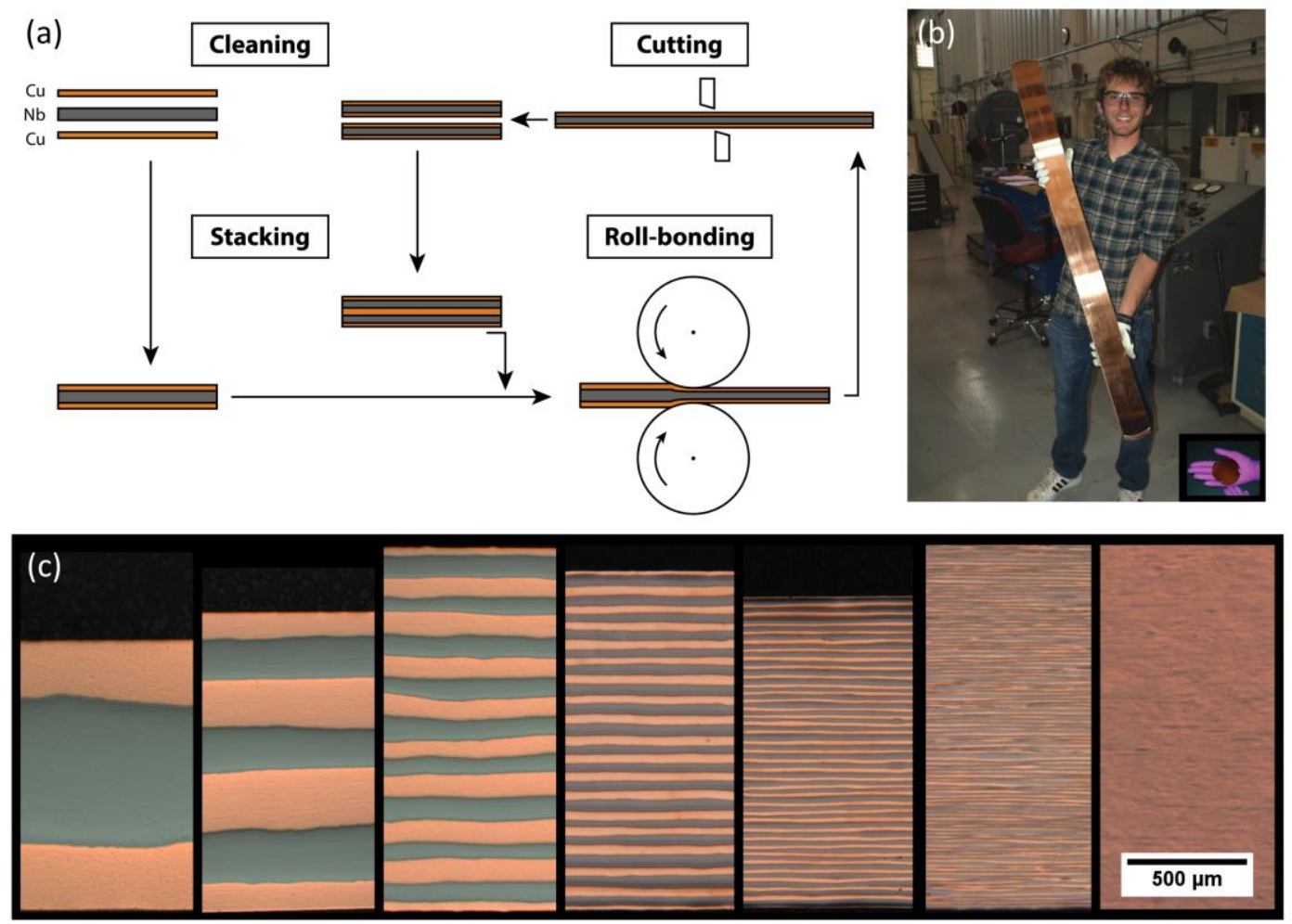

Figure 1: (a) Schematic of the ARB process. For the $\mathrm{Cu}-\mathrm{Nb}$ system, bonding is achieved during 50\%-60\% reduction in thickness in the bonding step. (b) Photograph of ARB material held by Tom Nizolek, LANL/UCSB summer student. Thickness of material is $\sim 4 \mathrm{~mm}$, but can be scaled up using industrial-sized equipment. Inset shows 20 
micron thick PVD film as a comparison. Both require $\sim 1$ day to fabricate. (c) Optical micrographs of $\mathrm{Cu}-\mathrm{Nb}$ ARB material from initial bonding step (far left) through 7 bonding steps (far right). The material can be further processed down to individual layer thicknesses $<10 \mathrm{~nm}$.[23]

The ARB process imposes rolling deformation. Rolling can stabilize certain crystallographic orientations, known as ideal rolling components. In principle, grains with ideal orientations can deform plastically via slip and twinning under rolling without crystallographically reorienting. Grains of non-ideal orientations, however, use slip and deformation twinning to reorient to a nearby ideal orientation. In the process, they distort but once an ideal orientation is reached, they maintain it with continued rolling deformation. As deformation proceeds, more grains within the microstructure attain ideal positions. After some amount of straining, the metal achieves a stable rolling texture. The rolling textures of the more common fcc metals and bcc metals, and even hcp metals $(\mathrm{Zr}, \mathrm{Be}, \mathrm{Mg})$, have been evaluated over the years and to date, can be easily recognized[2, 3, 37-39].

While particular orientations are preferred, particular orientation relationships are not obeyed grain-to-grain in the grain network. Under an applied deformation, such as rolling, the relative fractions of misorientations may change but they still remain dispersed. In a recent study using a 3D full-field crystal plasticity model and a separate mesh for the grain boundaries, it was found that the fraction of $\Sigma 3$ boundaries in a $\mathrm{Cu}$ grain structure increased after rolling, but many other coincident site lattice (CSL) boundaries formed as well[4]. In essence, a strongly preferred boundary character is not expected to emerge after extreme mechanical deformation.

In contrast, single- and two-phase composite metals fabricated by solidification or deposition techniques tend to form strong textures where one or more of the crystals are aligned in the same direction. For two-phase metals, a sharp texture in both phases can most often be linked to a preferred crystallographic interface character defined by the orientation relationship and adjoining interface planes. Cast eutectic $\mathrm{Cu}-\mathrm{Ag}$ joins the $\mathrm{Cu}$ and Ag crystals in either a cube-on-cube or twin orientation relationship with $\{111\}$ interface planes[40-42]. Physical Vapor Deposition (PVD) of $\mathrm{Cu}-\mathrm{Nb}$ creates either a Kurdjumov-Sachs or Nishiyama-Wasserman orientation relationship with the $\{111\}_{\text {fcc }}$ and $\{110\}_{\text {bcc }}$ compact planes making up the interface and the compact atomic directions aligned within the interface $(\mathrm{K}-\mathrm{S})$ or a few degrees rotated about the interface plane normal $(\mathrm{N}-\mathrm{W})$. Material systems, such as $\mathrm{Cu}-\mathrm{Nb}$ and $\mathrm{Cu}-\mathrm{Ag}$, have current and potential application in specialized applications such as high field magnets[43, 44]. They are further studied as model systems to investigate interfacial influences on material behavior due to the noteworthy control over the interfaces that form during the deposition or solidification process. Other thermodynamically driven systems of technological importance include the iron-cementite $\left(\mathrm{Fe}_{-} \mathrm{Fe}_{3} \mathrm{C}\right)$ interface, found in pearlitic steels. Depending strongly on variation in carbon content and quenching history, $\mathrm{Fe}^{-} \mathrm{Fe}_{3} \mathrm{C}$ interfaces can be thermodynamically driven towards the Pitsch-Petch orientation relation or the Bagaryatsky orientation relation[45]. 


\subsection{Development of stable orientations and orientation relationships in extreme strains}

To determine whether grains within a two-phase composite achieve the same set of ideal rolling orientations as grains in single-phase metals, the phase textures within the ARB composite were measured as a function of individual layer thickness (or equivalently strain)[30, 31]. The measurement was carried out using neutron diffraction so that the bulk texture over the entire sample could be assessed without the need for surface preparation or limitations on individual layer thickness.

From these measurements, it was found that the conventional rolling textures of the $\mathrm{Cu}$ and $\mathrm{Nb}$ phase eventually became unstable as strains reached extreme levels. As the layers refined from $45 \mu \mathrm{m}$ to $10 \mathrm{~nm}$, the deformation textures transition from one typical of $\mathrm{Cu}$ and $\mathrm{Nb}$ when rolled alone[3,46] (at micron layer thicknesses or strains of 1-4) to a much sharper texture (at the submicron layer thicknesses $<800 \mathrm{~nm}$ or strains greater than 7) [31]. Figure 2 shows EBSD maps of $t=86 \mathrm{~nm}$ material, where the strong atypical rolling texture is evident from the ND distribution. For comparison, we present in Figure 3 , neutron diffraction inverse pole figures (IPFs) for $\mathrm{Cu}$ and $\mathrm{Nb}$ for $\mathrm{t}=200 \mathrm{~nm}$. As shown, these are in good agreement with the textures measured by EBSD in Figure 2.

Post-rolling microstructural characterization was carried out to correlate this texture transition with the developing microstructure. The instability in the usual rolling texture correlated with a transition from multiple grains across a given layer, to a single grain through-thickness (below $\mathrm{h}=800 \mathrm{~nm}$ or so). For layer thicknesses between $\sim 800 \mathrm{~nm}$ and $\sim 50 \mathrm{~nm}$, the microstructures are comprised of layers spanned by one grain and containing many grains in plane that are extremely elongated in the rolling direction. 
(a)

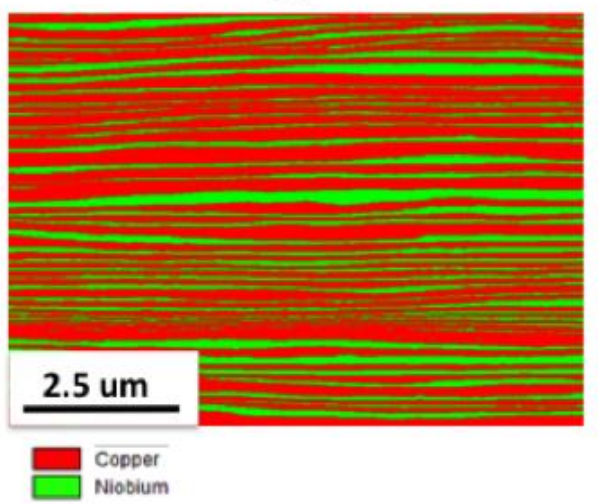

$\mathrm{Cu}$

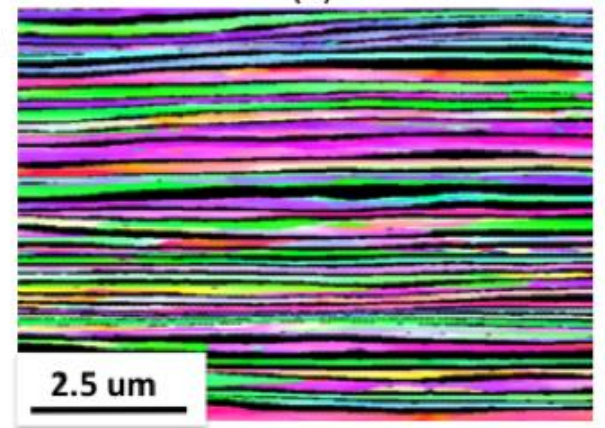

(c)

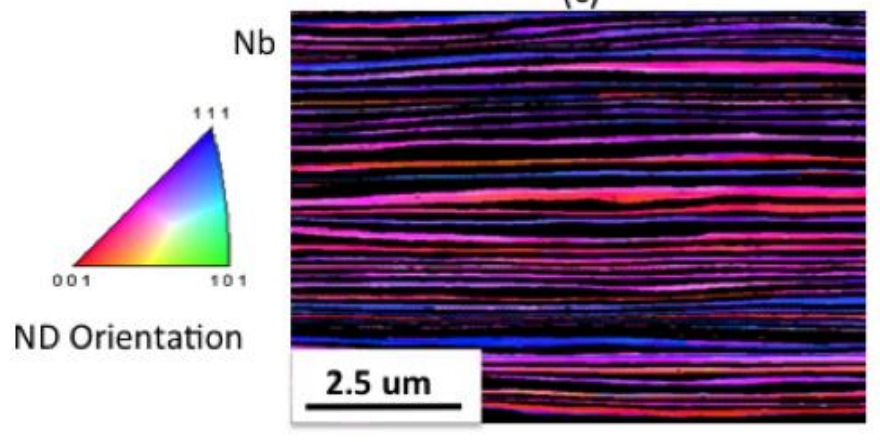

Figure 2: EBSD results from $\mathrm{t}=86 \mathrm{~nm}$ ARB $\mathrm{Cu}-\mathrm{Nb}$ sample. The sample was mounted at an inclined angle for increasing the apparent layer thickness per ref[35]. (a) phase map where red is $\mathrm{Cu}$ and green is $\mathrm{Nb}$. (b) and (c) are orientation maps where colors can be used to identify the orientation of the grains with respect to the normal direction by utilizing the included reference triangle[30]. 


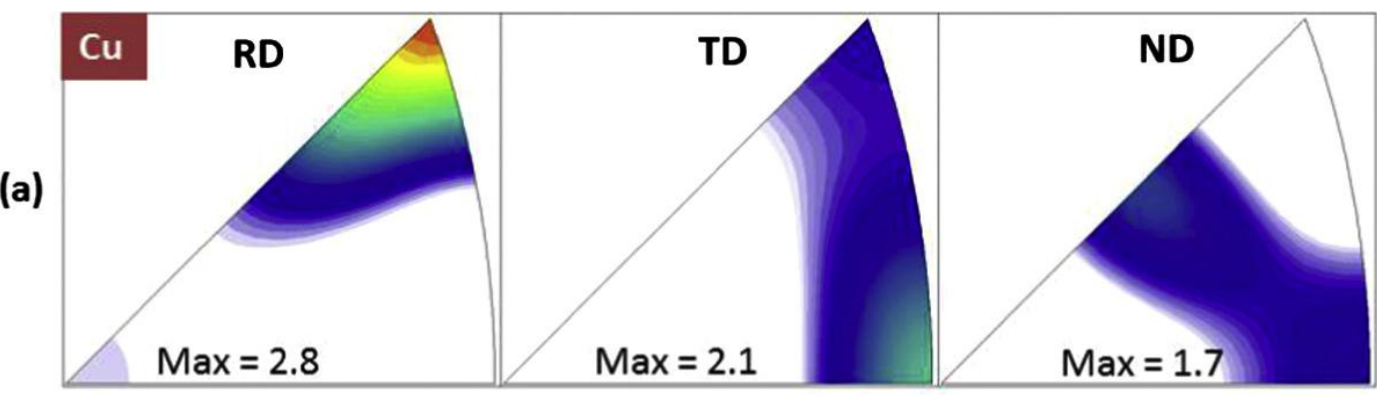

\section{0}

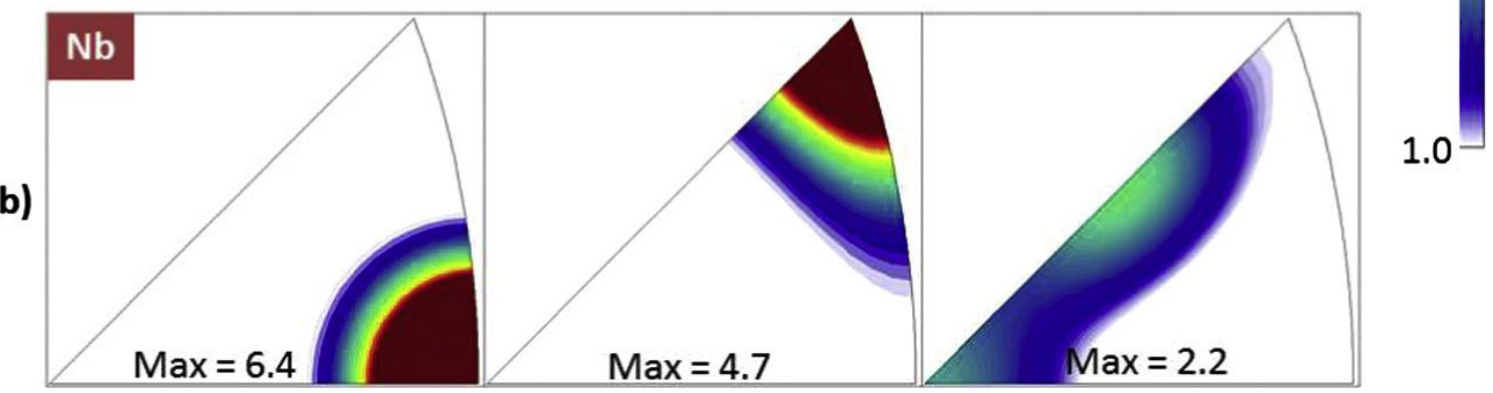

Figure 3: Inverse pole figures of the texture of the $\mathrm{Cu}$ and $\mathrm{Nb}$ phase in the nanocomposite with layer thickness $\mathrm{h}=200 \mathrm{~nm}$ as measured using neutron diffraction. The measurements show that the axes parallel to the ND range from (a) $\{112\}$ to $\{110\}$ in the $\mathrm{Cu}$ phase and (b) from $\{112\}$ to $\{001\}$ in the $\mathrm{Nb}$ phase. IPFs are shown instead of conventional ODF sections in order to bring out the sharpness of the textures and the crystallographic axes relative to the two-dimensional layered structure RD-TD-ND[31]. Pole figures and ODFs sections can be found in Ref[47].

Further texture analysis indicated that rather than exhibiting the 'complete' rolling texture with many ideal orientations, the $\mathrm{Cu}$ and $\mathrm{Nb}$ phase stabilized to a subset of a few selected ideal rolling orientations. The $\mathrm{Nb}$ crystals became highly oriented about the $\{112\}<110>$ component, within $\pm 15^{\circ}$, referred to as the I component in the literature, and likewise, the $\mathrm{Cu}$ crystals were narrowly distributed from the $\mathrm{C}\{112\}<111>$ component to the $\mathrm{D}\{4$ $411\}<11118>$ component (differing by an $8^{\circ}$ tilt). As strain increased (and layers refined close to $100 \mathrm{~nm}$ ), the $\mathrm{Cu}$ and $\mathrm{Nb}$ textures sharpened further about these few orientations. In light of the large number of possible ideal rolling components, it was unanticipated that the texture would stabilize to just a few orientations when refined to ultra-fine layer thickness and not towards the other common rolling orientations. Stabilization of preferred orientations different from those expected in single-phase rolling textures has been observed earlier in the cast and rolled $\mathrm{Cu}-\mathrm{Nb}$ system in [48-51]. Compared to these works, the deformation processes in the current ARB process involved much larger strains. A full discussion on texture development in these earlier systems, as well as the present ARB Cu-Nb system, can be found in [52]. Further, under the shear imposed by Equal Channel Angular Extrusion (ECAE) or rolling, Nb has proven to undergo localized shearing $[53,54]$, as have the bi-phase $\mathrm{Cu}-\mathrm{Ag}$ and $\mathrm{Cu}-\mathrm{Nb}$ systems [55]. Localized shear can give rise to textures that differ from those encountered as a result of homogeneous deformation. Shear banding can be readily observed in the $\mathrm{ARB} \mathrm{Cu}-\mathrm{Nb}$ at layer thicknesses above $\sim 1 \square \mathrm{m}$, although these features do not significantly disrupt the layered structure. Once the layer thicknesses drop below $1 \square \mathrm{m}$ 
and the layers are 1-2 grains in the thickness direction, the degree of waviness of the layers decrease, indicating a transition towards stable, homogeneous plasticity in the composite. As the material transitions from a wavy morphology driven by localized shear to a flatter, more uniform one, the interfacial character will change accordingly, and affect the resulting texture and propensity for chemical intermixing under subsequent strain. The consequences of localized shear and waviness at the higher length scales on mechanical properties, and their participation in texture evolution are not fully known. Future investigations into these processes would prove useful in developing these severe plastic deformation processes for target microstructure and mechanical properties.

Transition towards an unusually sharp texture for both phases suggested that the interfaces between them could be conforming to a particular orientation relationship. To explore this possibility, the five-parameter crystallographic character of $\mathrm{Cu}-\mathrm{Nb}$ interfaces in ARB samples with layer thickness in the range of $200 \mathrm{~nm}$ to $600 \mathrm{~nm}$ was first analyzed since this is the range in which the texture transition was first observed.

Several orientation and phase maps from EBSD were used to characterize the local heterophase interface character distribution (HICD) over large representative areas of the material[36]. In agreement with the neutron diffraction measurements, EBSD analysis confirmed that that the $\mathrm{Cu}$ phase was highly oriented between the $\mathrm{C}$ and $\mathrm{D}$ components and the $\mathrm{Nb}$ phase at the I component. More importantly, the analysis indicated that the $\{112\}<111>\mathrm{Cu} \|\{112\}<110>\mathrm{Nb}$ interface (or in short the $\mathrm{C} / \mathrm{I}$ interface) prevailed ubiquitously across the material. Deviations from this predominant interface character were about $15^{\circ}$. This includes the $\mathrm{D}$ component in $\mathrm{Cu}$ joined to the $\mathrm{I}$ component in $\mathrm{Nb}$ or the $\mathrm{D} / \mathrm{I}$ interface in brief.

The $\mathrm{C} / \mathrm{I}$ interface has the Kurdjumov-Sachs (KS) orientation relationship, which is the same fcc-bcc orientation relationship observed frequently in physical vapor deposited films [56] and duplex steels[57]. Its key distinction from prior observations, however, lies in the planes that comprise the interface. The stable interface that arises in extreme rolling strains joins the mutual $\{112\}$ planes of the fcc and bcc crystal, whereas the conventional KS interface found in PVD films and cast duplex steels joins the compact, more atomically dense $\{111\}_{\mathrm{fcc}}$ and $\{110\}_{\text {bcc }}$ planes.

Although not often, the C/I, has been observed previously in other systems. In earlier work, it had been reported that this $\mathrm{C} / \mathrm{I}$ interface forms between precipitates and matrix in a Ni-45Cr alloy[58]. There it was first noted that it was atomically faceted (with a zigzag morphology). More recently, the $\mathrm{C} / \mathrm{I}$ interface was observed in $\mathrm{Cu}-\mathrm{Nb}$ wires formed by accumulative wire drawing (AWD) [59, 60]. In Ref. [60], the authors found that it contained a regular array of misfit dislocations.

\subsection{Stability with respect to continued rolling}

With further straining via conventional rolling deformation, the material maintains the layered morphology and one-to-one $\mathrm{Cu}-\mathrm{Nb}$ thickness ratio and the layers refine from the submicron to the nanoscale. Consequently the interface density increases and it appears 
that the grain aspect ratio increases as well[33, 35]. It then became desirable to know whether the $\mathrm{C} / \mathrm{I}$ interface remained stable with respect to straining and whether more straining led to the creation of more $\mathrm{C} / \mathrm{I}$ interfacial content.

To address these questions, the interface character analysis thus had to be repeated on samples with nanolayer thicknesses (less than $100 \mathrm{~nm}$ ) formed by taking the submicron layered ARB material and subjecting it to conventional rolling. However for such fine layer thicknesses, it is necessary to use a more highly resolved microscopy technique than standard EBSD. A series of studies were carried out using either wedge-mounting (highresolution) EBSD or precession electron diffraction[35, 61], which can supply the simultaneous orientation and phase maps with step sizes of about $1 \mathrm{~nm}$ while maintaining angular resolution close to that of SEM-EBSD $\left(\sim 0.5^{\circ}\right)$. These analyses reported that indeed the $\mathrm{C} / \mathrm{I}$ interface remained the predominant interface in these finer layers (down to $30 \mathrm{~nm}$ ). Thus, the $\mathrm{C} / \mathrm{I}$ interface is stable with respect to further rolling deformation. In fact, it was preferentially created with more extreme mechanical straining[31].

\subsection{Other signatures of stability:}

The studies discussed above have shown that the crystallographic character of the interface is stable with respect to mechanical straining. With this in mind, it was also questioned whether finer scale structural features of the interface at the nanoscale and atomic scales were also stable. For instance, a regular atomic structure can serve as a sign of interface stability. Interfaces that are high in energy usually exhibit an atomically disordered structure and this structure tends to be unstable with respect to perturbations in thermal or mechanical energy. To examine the atomic structure of the interfaces in the ARB material, HR-TEM was employed. Figure 4 shows typical HR-TEM images, revealing that these interfaces are in fact atomically ordered and chemically sharp. The tendency for $\mathrm{Cu}$ and $\mathrm{Nb}$ to phase separate is strong. In fact, even after processing to sub$20 \mathrm{~nm}$ layer thicknesses, chemical intermixing is not detected via TEM, and via X-ray techniques, the intermixing has been quantified to be negligible within the resolution of the technique (less than 1\%). After further straining via other SPD techniques, such as High Pressure Torsion, intermixing remains extremely low until exceeding torsional strains of 10 (total strain is ARB strain of 10 plus additional torsional strain of 10)[62]. Furthermore, as reported for the $\mathrm{C} / \mathrm{I}$ interfaces in cast $\mathrm{Ni}-\mathrm{Cr}$ alloys, this interface is atomically faceted. Generally such atomic-scale regularity is reminiscent of the characteristic, low-energy interfaces formed in PVD or solidification techniques[63]. It is, however, not typical of interfaces after severe, thermo-mechanical (far from equilibrium) processing[7, 60, 64, 65] and hence the observation seen in Figure 4 was unexpected. 

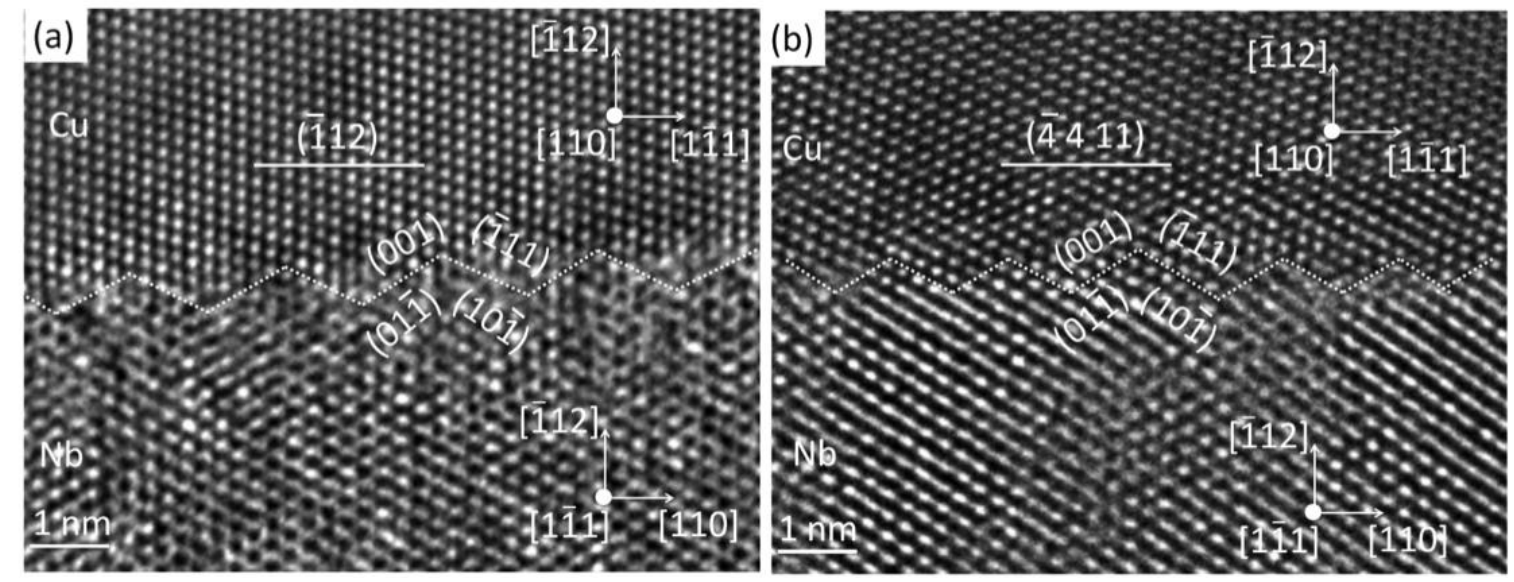

Figure 4: HR-TEM micrographs of pristine $\mathrm{Cu}-\mathrm{Nb}$ interfaces in nanolayered composites (layer thickness $<100 \mathrm{~nm}$ ) made by accumulative roll bonding. (a) the $\mathrm{C} / \mathrm{I}$ interface: the orientation of the top $\mathrm{Cu}$ crystal is $\mathrm{C}\{112\}<111\rangle$ and bottom $\mathrm{Nb}$ crystal is I $\{112\}\langle 110\rangle$, where $\{h k l\}$ refers to the interface plane and $\langle$ uvw $\rangle$ to the direction pointing to the right, along the rolling direction. (b) the D/I interface: a neighbor to $\mathrm{C} / \mathrm{I}$ misoriented by 7 degrees. The orientation of the top $\mathrm{Cu}$ crystal is $\mathrm{D}\left\{\begin{array}{lll}4 & 4 & 11\end{array}\right\}<11118>$ and bottom $\mathrm{Nb}$ crystal is I $\{112\}<110>[66]$.

MD simulation calculations of the interface also find that the relaxed structure to contain a regular array of facets[59, 67]. It was explained that for this interface, the two crystallographic planes before being joined are naturally faceted[68]. Both the D/I and $\mathrm{C} / \mathrm{I}$ interfaces and the intermediate interfaces deviating by a tilt are faceted[69].

The observed atomic-level order of the interface structure makes it amenable to the theoretical descriptions of a dislocation network, comprised of a few arrays of misfit dislocations. The arrays are regularly spaced and the dislocations are distinct, with welldefined cores that are less than the array spacing $[59,70]$. The interface regions between the misfit dislocations are coherent.

The foregoing studies discovered that a particular stable interface character arises during extreme mechanical straining. However, no theoretical basis exists that can clarify which interfaces would stabilize in these conditions. Based on the high density of interfaces achieved at high rolling strain levels, it was hypothesized that both plastic work and interface formation energy play a governing role. In recent work, a combination of crystal plasticity and atomistic modeling were carried out to understand the superior stability of the $\mathrm{C} / \mathrm{I}$ interface and closely oriented neighbor interfaces $[31,71]$.

It was found that the few prevailing interfaces that emerged in rolling were those that were orientationally stable in plastic deformation and corresponded to energetic minima in formation energy[71]. The former variable, orientation stability, was established using crystal plasticity simulations assuming that the crystals were deforming via slip and that the $\mathrm{Cu}$ and $\mathrm{Nb}$ were co-deforming[72]. If under the constraint of co-deformation, the crystals on both sides of the interface were able to mutually maintain their orientation, then their common interface would be able to preserve its crystallographic character and 
the interface would be considered 'plastically stable'. The latter variable of formation energy was calculated by applying molecular dynamics to a $\mathrm{Cu}-\mathrm{Nb}$ bicrystal[ $[69,71]$ and can be seen graphically in Figure 5. While many interfaces of differing OR and IP can be seen in this figure, the experimentally observed interfaces reside at local minima in the energy landscape. For example, a faceted interface misoriented slightly (less than half degree) from the $\mathrm{D} / \mathrm{I}$ interface and about $7^{\circ}$ from the $\mathrm{C} / \mathrm{I}$ interface was found to correspond to a cusp in formation energy landscape[73].

When plastic stability and formation energy were plotted for many candidate interfaces on a 2D map (Figure 6), it became readily apparent that the few interfaces that exhibited stability experimentally collected exclusively in the upper left-hand corner, the region that corresponds to interfaces with low formation energy and that are highly stable in codeformation.

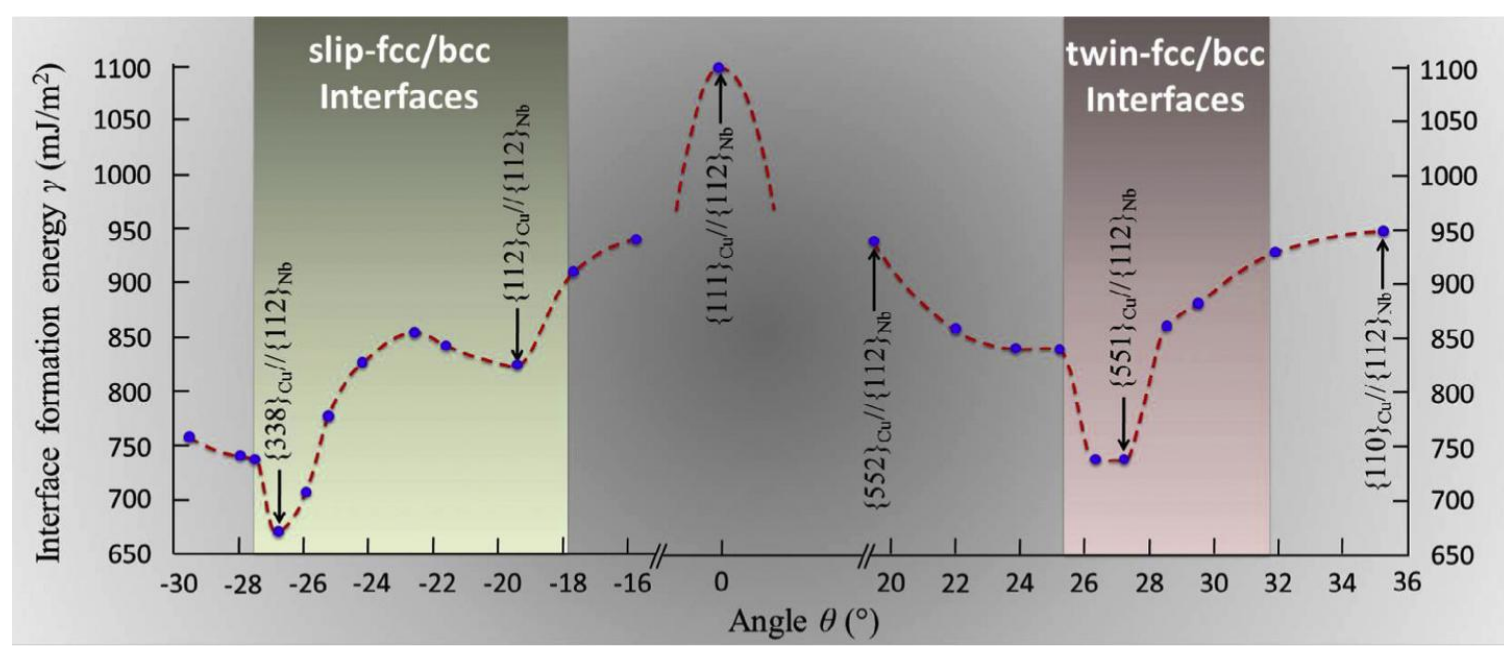

Figure 5: The preferred interfaces found in ARB $\mathrm{Cu}-\mathrm{Nb}$ composites correspond to local formation energy minima, regardless if their deformation is dominated by either slip or twinning. In this plot, the $\{111\} \mathrm{Cu} / /\{112\} \mathrm{Nb}$ interface is taken as the zero point, and the $\mathrm{Cu}$ layer is rotated by an angle theta about the axis normal to the HRTEM micrograph in Figure $4 \mathrm{a}[31]$.

Other interfaces, not experimentally seen, lay in remaining parts of the map, the 'unstable' regions. Some of these unseen interfaces are calculated to be stable in codeformation but at the same time correspond to high-energy interfaces (upper right-hand corner). Presumably the latter aspect prevented these interfaces from persisting under extreme deformation. Similarly other unseen interfaces are those that have low formation energies, which would be created in solidification or phase transformations or deposition. While these are characteristically low in formation energy, they were calculated to be unstable when rolled (lower left-hand corner). This means that under deformation one or both crystals in the pair rapidly reoriented, and in some cases formed orientation gradients. The shared interface lost its original interface character. 


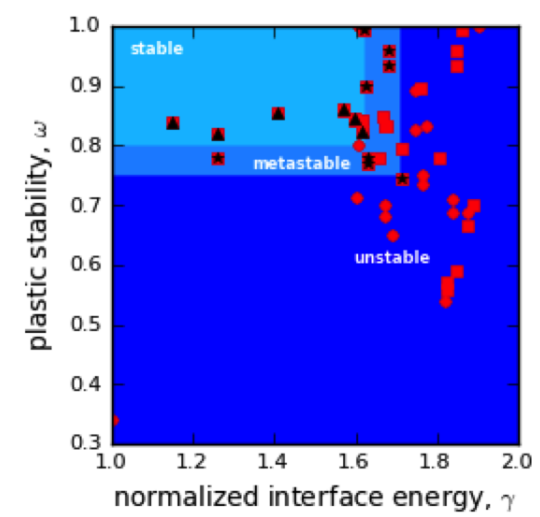

Figure 6: Interface character stability map. The x-axis represents interface energy and the $y$-axis represents stability in character under co-deformation. Squares represent interfaces created by pairing orientations from the stable orientation distribution (i.e., well-developed rolling texture for the single-phase metal) of the deformed crystals. Circles represent interfaces formed when one or both orientations do not belong to the theoretical single-phase rolling texture. Interfaces with black triangles represent the observed predominant slip fcc/bcc interfaces and with black stars the observed twinfcc/bcc interfaces[31].

\subsection{Stability with respect to nano-enabled deformation twinning}

As the layers reduced below 50-60 nm, deformation twins started to form in the $\mathrm{Cu}$ phase. The deformation twins at first occurred heterogeneously across the sample. As layers refined to $\mathrm{h}=10 \mathrm{~nm}$, the volume fraction reached $30 \%$, which would be considered profuse[31, 74]. Deformation twinning in nanocrystalline $\mathrm{Cu}$ is a well-known phenomenon. At room temperature and quasi-static deformation strains, $\mathrm{Cu}$ twinning has been reported in several other nanocrystalline, or single-phase or two-phase nanostructured systems $[75,76]$. It has also been predicted numerically to occur easily from grain boundaries in nanocrystals ranging from $10 \mathrm{~nm}$ to $100 \mathrm{~nm}$ in size [77, 78]. While twinning is expected in nanocrystals of $\mathrm{Cu}$, it does not occur in nanocrystals of $\mathrm{Nb}$. Consequently, the twin-oriented parts of the $\mathrm{Cu}$ crystal and same untwinned $\mathrm{Nb}$ crystal form an interface that is distinctly different from the $\mathrm{C} / \mathrm{I}$ interface. The question then is, what is the stability of this new interface with respect to further straining?

Using microstructural characterization across atomic to meso scales, it was found that subsequent mechanical straining can drive the post-twinned interfaces to attain another set of stable interfaces, ranging over a span of $8^{\circ}$ from the $\{551\}<1 \quad 1$ $10>\mathrm{Cu} \|\{112\}<110>\mathrm{Nb}$ interface to the $\{110\}<001>\mathrm{Cu} \|\{112\}<110>\mathrm{Nb}$, or Goss-I interface $[31,73]$. A HR-TEM image of twinning-driven interfaces is presented in Figure 7. As shown, we find that the mechanically driven interface after twinning possesses a regular atomic structure with no obvious signs of dislocation storage or debris. They are comprised of a regular array of facets, much like the interface in Figure 4, although the facet planes are different[79]. Moreover, the new, twinned $\{551\}<1 \quad 1$ 
$10>\mathrm{Cu} \|\{112\}<110>\mathrm{Nb}$ interface proves to be an energetically favorable one, corresponding to a cusp on the energy landscape of Figure 5.

The foregoing results show that even when crystals plastically deform by slip and twinning, a stable, preferred interface can be attained in extreme strains. Further, regardless of their association with slip or twinning the stable interfaces reside at local minima in formation energy (Figure 5). As such, one can further hypothesize that the energetically favorable interfacial structures produced under extreme straining will continue to be stable under other extreme conditions such as elevated temperatures and ion irradiation. The subsequent sections test this hypothesis.

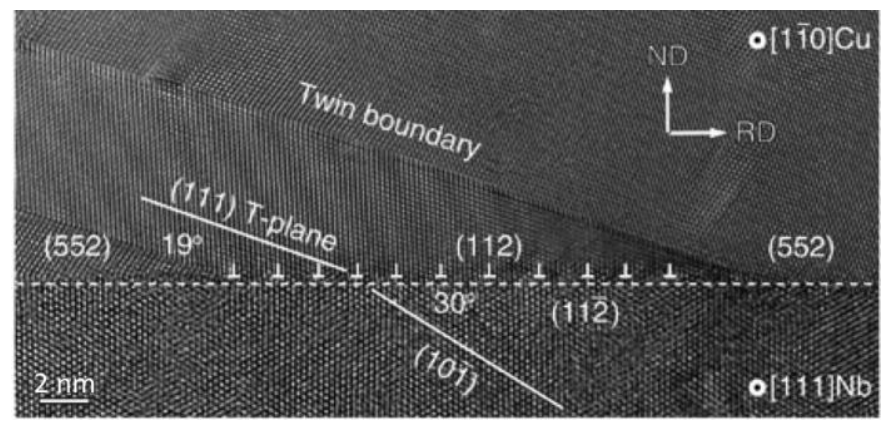

Figure 7: An example of twinning in 30 $\square$ nm layer thickness $\mathrm{ARB} \mathrm{Cu} \mathrm{Nb}$, showing the initial interface $\quad\{112\}<111>\mathrm{Cu} \|\{112\}<110>\mathrm{Nb}$ and the interface $\{552\}<115>\mathrm{Cu} \|\{112\}<110>\mathrm{Nb}$ after twinning[73].

\subsection{Microstructural stability under extreme temperatures}

The microstructure and hardness of the ARB material was tested after exposure to high temperature in order to examine its thermal stability. After static high-temperature annealing of up to $500^{\circ} \mathrm{C}$ (Figure 8), both the layered morphology, with no signs of layer pinch-off, and the faceted structure of the interfaces were preserved. In addition, the high hardness of $4.07 \pm 0.4 \mathrm{GPa}$ was maintained. This result shows that this $\mathrm{Cu}$-based nanostructured material has exceptional thermal stability, even at temperatures nearly half the melting temperature of $\mathrm{Cu}$.

The outstanding thermal stability can be correlated to the stability of the interfaces. The microstructure of the ARB material in Figure 8a contains predominantly two types of interfaces, the $\mathrm{C} / \mathrm{I}$ interface and the $\{551\}<1 \quad 1 \quad 10>\mathrm{Cu} \|\{112\}<110>\mathrm{Nb}$ "twinned" interface, both of which possess relatively low formation energies. Other materials with relatively low interfacial formation energies such as nanotwinned $\mathrm{Cu}$ and PVD $\mathrm{Cu}-\mathrm{Nb}$ exhibit enhanced thermal stability approaching that of the ARB $\mathrm{Cu}-\mathrm{Nb}$ presented here[56, 80]. Other $\mathrm{Cu}$-based nanomaterials do not share in this unique resistance to microstructural instability at elevated temperatures. For instance, gas deposited $15 \mathrm{~nm}$ grain size nanocrystalline $\mathrm{Cu}[81]$ and PVD $20 \mathrm{~nm} \mathrm{Mo} / \mathrm{Pt}$ multilayers[82] undergo microstructural coarsening and subsequent degradation of mechanical hardness after similar annealing cycles. 

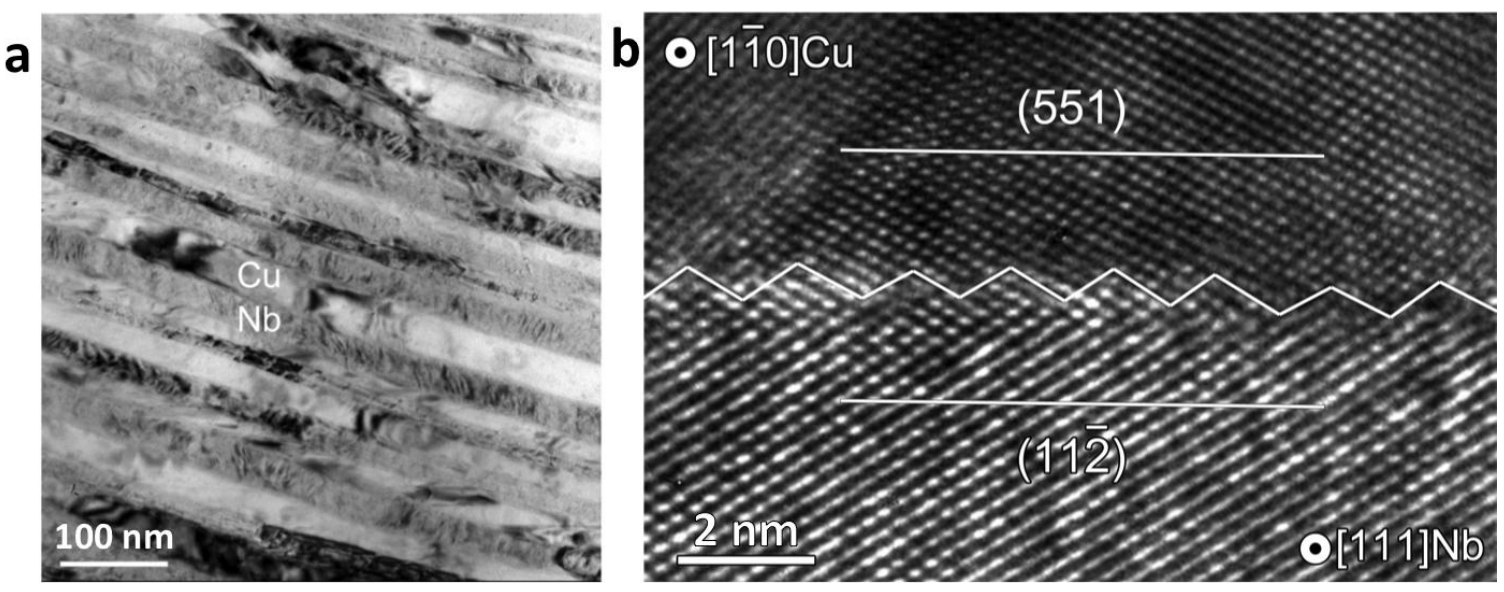

Figure 8: (a) Cross-sectional bright field TEM image of $\mathrm{Cu}-\mathrm{Nb} 10 \mathrm{~nm}$ layer thickness $\mathrm{ARB}$ material after annealing at $500^{\circ} \mathrm{C}$ for 1 hour. (b) faceted twinned $\mathrm{Cu}-\mathrm{Nb}$ interfaces are still evident after this annealing treatment, as evidenced by HRTEM[73].

To study the stability of the interface after exposure to extreme heat, $\mathrm{Cu}-\mathrm{Nb} \mathrm{ARB}$ material with $\mathrm{t}=18 \mathrm{~nm}$ was annealed step-wise in-situ in a neutron beam up to $900^{\circ} \mathrm{C}$. This annealing schedule exposed the $\mathrm{t}=18 \mathrm{~nm}$ ARB material to elevated temperatures up to $0.86 \mathrm{~T}_{\mathrm{m}}$ of $\mathrm{Cu}$ for 8.75 total hours. After this extreme heating schedule, postcharacterization found the coarsened, layered microstructure of Figure 9b. A remarkable finding was the sharpening of texture in both the $\mathrm{Cu}$ and $\mathrm{Nb}$ phases about the $\mathrm{C} / \mathrm{I}$ orientation relationship. This is shown in Figure 9c and 9d, which presents the IPFs after an annealing cycle to $500^{\circ} \mathrm{C}, 600^{\circ} \mathrm{C}, 700^{\circ} \mathrm{C}, 800^{\circ} \mathrm{C}$, and $900^{\circ} \mathrm{C}$ for 105 minutes at each step. Therefore, despite the extreme conditions and the coarsening of the layers, the layered morphology and the $\mathrm{C} / \mathrm{I}$ interface were preserved. Thus, the $\mathrm{C} / \mathrm{I}$ interface found stable in the as-processed material was also stable in high-temperature annealing.

As mentioned, although the predominant $\mathrm{C} / \mathrm{I}$ interface was stable under extreme heat, the layer thickness still coarsened once temperatures exceeded $600^{\circ} \mathrm{C}$. The mechanism of microstructural instability and coarsening at higher temperatures depends sensitively on the microstructure. While for the same layer thickness, the material made by $\mathrm{Cu}-\mathrm{Nb}$ PVD exhibited nearly similar thermal stability as the $\mathrm{Cu}-\mathrm{Nb}$ ARB material, the thermally induced instabilities were not the same. Prior work on PVD $\mathrm{Cu}-\mathrm{Nb}[30,32,56,83,84]$ showed that microstructure instability was tied to in-plane grain boundary migration and the formation of an offset-layered structure, followed by layer pinch-off due to grain boundary grooving at triple points at higher temperatures. The in-plane grain aspect ratios were small, ranging from 1 to 3 and the interface planes were atomically flat, being the atomically dense planes with orientation relationship $\{111\}<110>\mathrm{Cu} \|\{110\}<111>\mathrm{Nb}$.

For the ARB material, the microstructure cannot break down in a similar way. In the asprocessed $\mathrm{ARB}$ material with the $\mathrm{C} / \mathrm{I}$ and twinned interfaces, in-plane grain aspect ratios are large, with grains exceeding lengths of ten microns. Consequently, very few grain boundaries will be evident in a typical TEM micrograph, such as Figure 9a. In an effort 
to gain insight into the onset of thermal instability in this distinctive microstructure, TEM analyses of $\mathrm{t}=10 \mathrm{~nm}$ and $20 \mathrm{~nm}$ ARB material after exposure to $500^{\circ} \mathrm{C}$ for 1 hour was carried out[85]. For very thin layers of $8 \mathrm{~nm}$ or less, the $\mathrm{Nb}$ phase exhibited pinch-off that was not associated with pre-existing grain boundaries and instead occurred within a given grain in the $\mathrm{Nb}$ phase. This points to a different mechanism driving the onset of thermal instability than the well-understood grain boundary grooving that arises in the PVD foils due to the difference between grain boundary energy and the interface energy[86, 87]. Instead, incipient instability in the ARB material was associated with two key microstructural observations: 1) the orientation relationship between $\mathrm{Cu}$ and $\mathrm{Nb}$ did not correspond to a predominant low-energy interface and 2) local faceting along low energy planes in layers undergoing pinch-off or local necking[85]. Given these observations it was found that under heating the relatively higher energy interfaces are prone to forming facets consisting of lower energy planes. The facets create local perturbations in layer thickness that appear as periodically occurring necked regions along the extremely elongated high-aspect ratio grains, and can lead to a classical Rayleigh instability. Specifically, the facets introduce a gradient in chemical potential along the interface that drives the diffusion of atoms from the necked region to the originally planar regions. As the instability progresses, the necked regions become discontinuous, and the material from the two adjoining layers flows in and forms a grain boundary where the original intermediate layer once existed. As such, two high-energy, $\mathrm{Cu}-\mathrm{Nb}$ planar interfaces are replaced by one low-energy $\mathrm{Cu}-\mathrm{Cu}$ grain boundary. In this way, the microstructure evolves to minimize its total energy, and higher energy boundaries that are not part of the predominant family of stable bimetallic interfaces are consumed. This process of eliminating the higher energy and hence less stable bimetal interfaces is consistent with observations reported in the in-situ annealing experiments to $900^{\circ} \mathrm{C}[32]$, where the texture components associated with low-energy interfaces significantly strengthen, even though the microstructure has pinched off and coarsened.
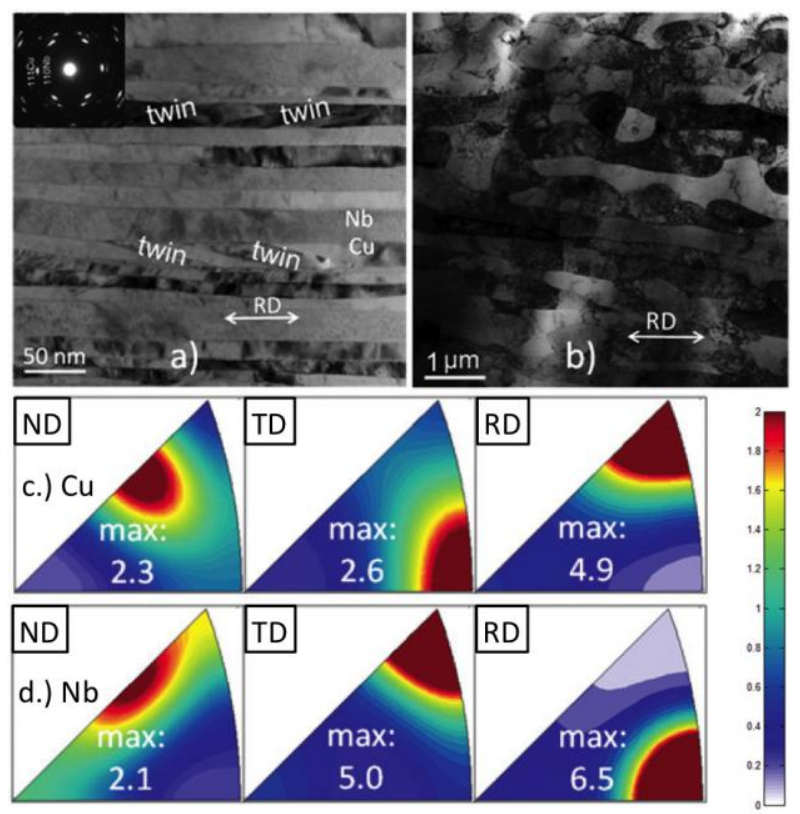
Figure 9: TEM images of 18nm layer thickness $\mathrm{Cu}-\mathrm{Nb}$ ARB material (a) before and (b) after annealing to $900^{\circ} \mathrm{C}$. (c) and (d) are neutron diffraction IPFs for the ND, TD, and $\mathrm{RD}$ showing the remarkable sharpness of texture in $\mathrm{Cu}$ and $\mathrm{Nb}$ respectively, even after annealing to $0.86 \mathrm{~T}_{\mathrm{m}}$ for Copper. The peak intensities are plotted in units of multiples of random, and correspond with those expected for the C/I orientation relationship[32].

On this basis, one can envision using thermomechanical processing in such as way as to produce even more homogeneous microstructures than what has been presented here. An example would be to start with the $18 \mathrm{~nm}$ material in Figure 9a, anneal to sharpen the interfaces about the C/I-type, and then further ARB process to the desired layer thickness. With the enormous parameter space associated with the choices of bimetal constituents, layer thicknesses, and strain paths, the potential control over stable microstructures using ARB combined with subsequent annealing steps is unprecedented, and is only beginning to be explored in a systematic fashion.

As mentioned in the last section, the strain path used in processing is a variable that could be used to control the crystallography of the interfaces that stabilize after extreme straining. As a first attempt to test this notion, we compare an interface that stabilizes during rolling in one direction with one that stabilizes under cross-rolling. The two cases began with the $\mathrm{t}=58 \mathrm{~nm} \mathrm{Cu}-\mathrm{Nb}$ ARB processed material that was then refined to $\mathrm{t}=20$ $\mathrm{nm}$ via one of two strain paths: a) maintaining the rolling direction (LR or longitudinally rolled), or b) rotating the workpiece $90^{\circ}$ about the ND (CR or cross-rolling)[33]. Neutron diffraction revealed that the $\mathrm{t}=20 \mathrm{~nm}$ LR material consisted of the expected textures consistent with a mix of the $\mathrm{C} / \mathrm{I}$ interface and some predominant twinned interfaces $\{110\}<001>\mathrm{Cu} \|\{112\}<110>\mathrm{Nb}$ discussed earlier in Figures 8b (twin HRTEM) and below in Figure 10c. The CR material, however, exhibited a strikingly different texture that corresponded to the formation of a new predominant interface, shown in Figure 10d. In comparison with the $\mathrm{C} / \mathrm{I}$ interfaces in Figure $10 \mathrm{c}$, this new interface is in the Nishiyama-Wasserman (N-W) orientation relationship, and is found to be atomically flat via HRTEM. Moreover, frequent deformation twins are found in the LR material, whereas the $\mathrm{CR}$ material has very few. Past investigations have discovered that the faceted $\mathrm{C} / \mathrm{I}$ interfaces and grain orientations favor deformation twinning, where the $\mathrm{N}-\mathrm{W}$ interfaces in the CR material do not $[79,88]$. 

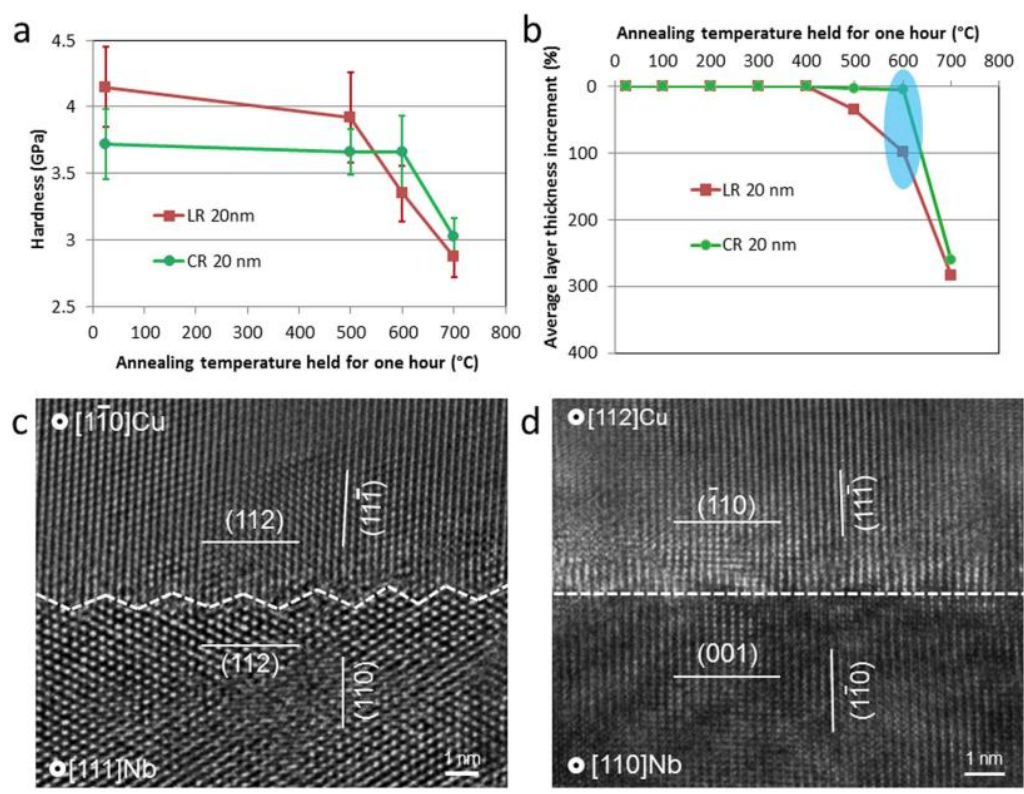

Figure 10: $20 \mathrm{~nm}$ layer thickness $\mathrm{Cu}-\mathrm{Nb}$ shows remarkable thermal stability at extreme temperatures. (a) Nanohardness of Longitudinally Rolled (LR) and Cross Rolled (CR) material as a function of one hour annealing temperature. (b) Layer coarsening of LR and CR materials as a function of one hour annealing temperature. Note that the CR material exhibits enhanced stability with respect to the LR material. (c) LR interface after $600^{\circ} \mathrm{C} 1$ hour anneal and (d) $\mathrm{CR}$ interface after $600^{\circ} \mathrm{C} 1$ hour anneal are identical to those interfaces found prior to annealing[33].

Another remarkable finding in this study is shown in Figure 10 (a, b). After a one-hour anneal at various temperatures, both the layer thickness and room temperature nanohardness of the CR material was found to be more stable than the LR material. After a $600^{\circ} \mathrm{C}$ anneal for one hour, both the LR and CR local interfacial structures were stable, but the layer thickness in the LR material had doubled, compared to the CR material, whose layer thickness remained unchanged. From the PVD $\mathrm{Cu}-\mathrm{Nb}$ studies discussed earlier, the most likely sites for thermal instability reside at grain boundaries within a given layer. In this ARB work, the LR grains have an RD:ND:TD ratio of 33:1:7 and 83:1:16 in the $\mathrm{Cu}$ and $\mathrm{Nb}$ respectively. In contrast, the $\mathrm{CR}$ material has a grain width three times that of the LR grains. That is, the content of homophase grain boundaries in the CR material is one-third that of the LR material, reducing the tendency for thermal instability via pinch-off at grain boundaries. Moreover, the CR material predominant interface is atomically flat, which could contribute to resistance to the faceting that drives Rayleigh instability in Reference [85].

\subsection{Microstructural stability under radiation extremes}

Nanoscale materials have been of interest to the radiation damage community due to recent work where Oxide Dispersion Strengthened (ODS) Fe-based nanocomposites[89, 90] exhibited enhanced radiation damage tolerance. These findings point to the fact that materials with high densities of interfacial content can provide sites for the annihilation/recombination of irradiation-induced point defects, vacancy clusters, and 
dislocation content. An outstanding question is how atomic interfacial character influences the physics of interface-defect interactions and the relative sink strength of interfaces in the presence of radiation-induced defects. The results of an initial investigation into this growing field are shown in Figure 11[10]. Cu-Nb ARB material with $20 \mathrm{~nm}$ individual layer thickness is compared with nanocrystalline $\mathrm{Cu}$. Both materials have undergone $\mathrm{He}$ ion irradiation at $450^{\circ} \mathrm{C}$, where the incident ions pass completely through the material, but produce $\sim 3$ dpa (displacements per atom) irradiation damage. This damage can be quantified via TEM as voids that coalesce from the irradiation cascades. In contrast with the extensive void formation at grain boundaries in nanocrystalline $\mathrm{Cu}$, the ARB material exhibits no voids in the microstructure, except at the center of the larger $\mathrm{Cu}$ layers. Such observations imply that while both $\mathrm{Cu}-\mathrm{Nb}$ ARB interfaces and $\mathrm{Cu}$ grain boundaries are suitable sinks for irradiation-induced defects, the $\mathrm{Cu}-\mathrm{Nb}$ material possesses the ability to annihilate such defects, whereas $\mathrm{Cu}$ grain boundaries do not.

The finding that the thicker $\mathrm{Cu}$ layers contain voids in the center of the layers, but in not the interfaces provides an opportunity to observe the sink strength of a given interface by measuring the thickness of the void depleted zone (VDZ) emanating from the interface. Using techniques such as precession electron diffraction (PED) and TEM, the VDZ for different interface types in $\mathrm{Cu}-\mathrm{Nb}$ and nanocrystalline Copper was evaluated. While the VDZ width for non $\Sigma 3 \mathrm{Cu}$ grain boundaries and $\Sigma 3$ incoherent twin boundaries exhibited values between 20 and $70 \mathrm{~nm}$, these boundaries were decorated by voids as seen in Figure 11b. The ARB material interfaces provided VDZ widths between $15 \mathrm{~nm}$ and 25 $\mathrm{nm}$ with no voids observed at the interfaces. While much work remains to be done on the mechanisms that enable radiation damage tolerance in nanolayered composites, especially under heavy ion or neutron irradiation, this first investigation has shown that the specific interface structures found in ARB $\mathrm{Cu}-\mathrm{Nb}$ nanocomposites possess both the ability to annihilate irradiation-induced defects, as well as a high sink strength. Microstructures containing high interface content are a necessary, but insufficient criterion for designing radiation-damage tolerant nanostructures. Clearly, interface structure also plays an important role here, and given the design space of composite morphology, compositions and interface types, interface structures that provide for unprecedented radiation damage tolerance may still be discovered.
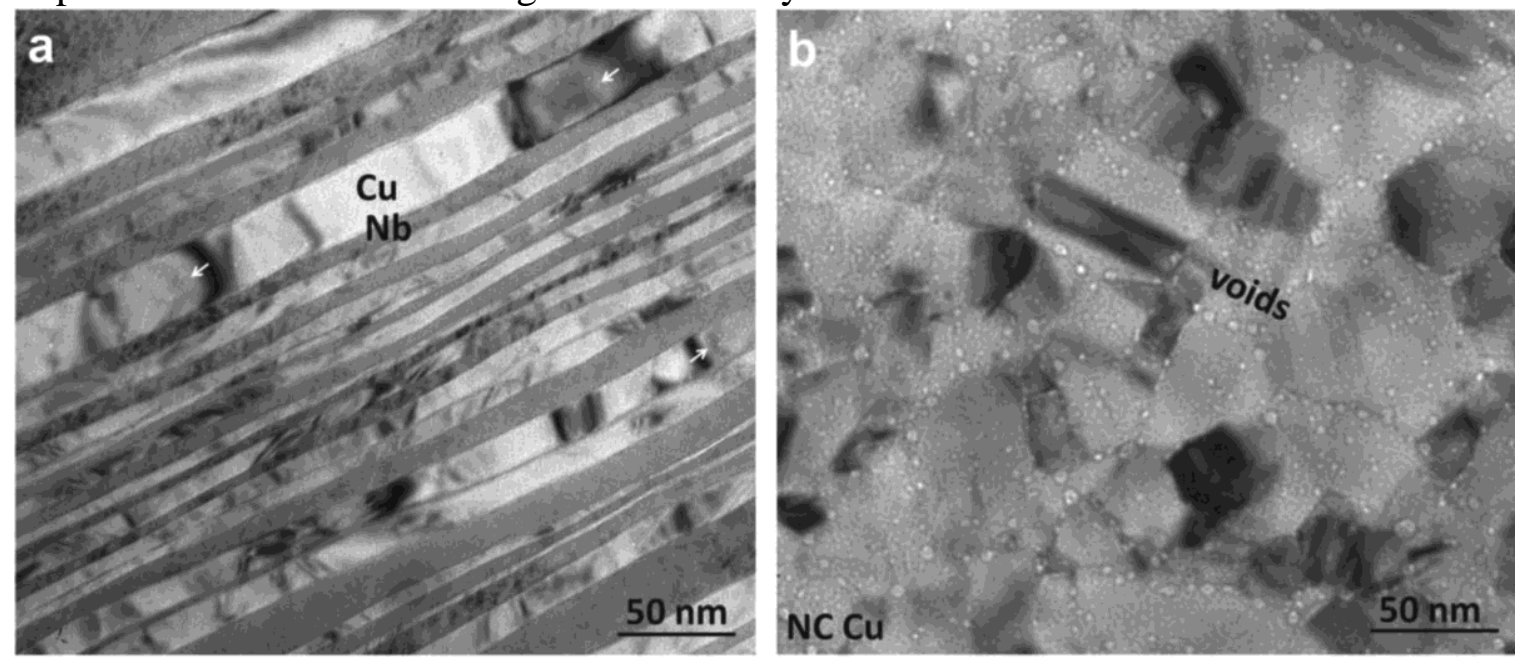
Figure 11: (a) Irradiated ARB NL Cu-Nb composites with $20 \mathrm{~nm}$ individual layer thickness are nearly void free. Arrows indicate small, isolated voids in the thicker $\mathrm{Cu}$ layers. (b) Irradiation damage in nanocrystalline $\mathrm{Cu}$ under identical conditions[10].

\subsection{Recommendations for future developments and studies}

In this work, we have presented an overview of recent progress on the stability of interface-dominant materials in seemingly distinct extreme conditions: very large strains, radiation, and elevated temperatures. A critical finding centers on the discovery that predominant interfacial characters can arise during extreme straining. Stable interfaces that form during $\mathrm{ARB}$ processing undergo little to no crystallographic rotation during further straining, and also tend towards local formation energy minima in the energy landscape. When both criteria are met, a stable microstructure, with preferred interface characters results.

We have shown that a microstructure produced under extreme strains tends to exhibit stability under other extremes, such as irradiation or temperature. The studies presented over the past approximately five years show great promise for this class of materials to enhance performance of materials in extreme conditions by at least an order of magnitude, depending on the property of interest. In the case of radiation damage tolerance, current work needs to be extended from light-ion to heavy-ion or neutron irradiation, as the defect populations can differ considerably depending on irradiation type and conditions, not to mention the interface type and density chosen. In the case of robustness in structural properties, thermal stability tests show similar potential for future work into thermal creep[91, 92], high-temperature processing (e.g. hot rolling), joining[93], and elevated-temperature forming.

It has been surmised for decades[94] that boundary character can profoundly influence the key unit processes of defect nucleation, mobility, storage, blocking and annihilation. Atomistic simulation tools have provided great insight into investigating the influences of atomic-level interface character on critical processes, and with increased computing power, can handle increased defect populations [95]. The parameter space for a matrix to study all interfaces at the atomic level is large, and relies on having the interatomic potentials and computing power required to undertake such an endeavor. Moreover, the experimental thermomechanical processing matrix is equally daunting.

What is lacking is an atomistically informed mesoscale model that can predict the family of stable interfaces that will arise during composite SPD processing, and can then be extended to guide production of technologically relevant alloys for engineering applications. Specifically the findings presented here call for a better understanding of the collaborative roles of the nanostructure, dislocation slip, deformation twinning, and the bimetal interface on the dynamics of deformation. Meso-scale techniques that integrate atomic-level physics associated with interface character have tremendous potential to address these issues. They treat the time and length scales corresponding to laboratory conditions, typically used in bulk metal working processes. The meso-scales 
are also relevant to understanding the effects of interfaces on texture and interface crystallography development. Recent crystal plasticity finite element models, using 2D and 3D microstructures taken from experimental characterization, have been developed to account for co-deformation and/or slip transmission across a bimetal interface[72, 96]. They have demonstrated that these effects have profound influence on the stability of interface character and texture during plastic deformation[66]. Currently, the effort to integrate the atomic-level physics of defect-interface interactions into larger scale models is in its infancy. If this effort to develop experimentally validated meso-scale were expanded, it will provide a critical tool for predicting the interfaces that will arise under a given thermomechanical processing schedule, and in turn, the enhanced properties that result from the designed composite structure.

\section{Acknowledgements}

The authors gratefully acknowledge funding from the Los Alamos National Laboratory Laboratory Directed Research and Development program for support. This work was performed, in part, at the Center for Integrated Nanotechnologies, an Office of Science User Facility operated for the U.S. Department of Energy (DOE) Office of Science. Los Alamos National Laboratory, an affirmative action equal opportunity employer, is operated by Los Alamos National Security, LLC, for the National Nuclear Security Administration of the U.S. Department of Energy under contract DE-AC52-06NA25396.

\section{References:}

1. Beyerlein, I.J. and Toth, L.S., Texture evolution in equal-channel angular extrusion. Progress in Materials Science, 2009. 54: p. 427-510.

2. Randle, V. and Engler, O.E., Introduction to texture analysis : macrotexture, microtexture and orientation mapping / Valerie Randle and Olaf Engler, ed. Ebooks, C. 2000: Gordon and Breach Science Publishers, c2000. 388.

3. Kocks, U.F., Tome, C.N., and Wenk, H.-R., Texture and anisotropy : preferred orientations in polycrystals and their effect on materials properties / U.F. Kocks, C.N. Tome, H.-R. Wenk, authors and editors ; with additional contributions by A.J. Beaudoin ... [et al.] ; and with an introduction by H. Mecking. Preferred orientations in polycrystals and their effect on materials properties. 1998: Cambridge University Press, 1998. 676.

4. Knezevic, M., Drach, B., Ardeljan, M., and Beyerlein, I.J., Three dimensional predictions of grain scale plasticity and grain boundaries using crystal plasticity finite element models. Computer Methods in Applied Mechanics and Engineering, 2014. 277: p. 239.

5. Nazarov, A.A., On the role of non-equilibrium grain-boundary structure in the yield and flow stress of polycrystals. Philosophical Magazine A, 1994. 69(2): p. 327-340.

6. Valiev, R., Nanostructuring of metals by severe plastic deformation for advanced properties. Nature Materials, 2004. 3(8): p. 511-516. 
7. Valiev, R.Z. and Langdon, T.G., Principles of equal-channel angular pressing as a processing tool for grain refinement. Progress in Materials Science, 2006. 51(7): p. 881-981.

8. Ames, M., et al., Unraveling the nature of room temperature grain growth in nanocrystalline materials. Acta Materialia, 2008. 56(16): p. 4255-4266.

9. Malow, T.R. and Koch, C.C., Grain growth in nanocrystalline iron prepared by mechanical attrition. Acta Materialia, 1997. 45(5): p. 2177-2186.

10. Han, W., et al., Design of Radiation Tolerant Materials Via Interface Engineering. Advanced Materials, 2013. 25(48): p. 6975-6979.

11. Tench, D. and White, J., Enhanced tensile strength for electrodeposited nickelcopper multilayer composites. Metallurgical Transactions A (Physical Metallurgy and Materials Science), 1984. 15A(11): p. 2039-40.

12. Josell, D. and Spaepen, F., Determination of the interfacial tension by zero creep experiments on multilayers. I. Theory. Acta Metallurgica et Materialia, 1993. 41(10): p. 3007-15.

13. Josell, D. and Spaepen, F., Determination of the interfacial tension by zero creep experiments on multilayers. II. Experiment. Acta Metallurgica et Materialia, 1993. 41(10): p. 3017-27.

14. Josell, D., van Heerden, D., Read, D., Bonevich, J., and Shechtman, D., Tensile testing low density multilayers: aluminum/titanium. Journal of Materials Research, 1998. 13(10): p. 2902-9.

15. Misra, A., et al., Structure and mechanical properties of $\mathrm{Cu}-\mathrm{X}(\mathrm{X}=\mathrm{Nb}, \mathrm{Cr}, \mathrm{Ni})$ nanolayered composites. Scripta Materialia, 1998. 39(4-5): p. 555-560.

16. Anderson, P.M., Foecke, T., and Hazzledine, P.M., Dislocation-based deformation mechanisms in metallic nanolaminates. MRS Bulletin, 1999. 24(2): p. 27-33.

17. Mara, N.A., Bhattacharyya, D., Dickerson, P., Hoagland, R.G., and Misra, A., Deformability of ultrahigh strength $5 \mathrm{~nm} \mathrm{Cu} / \mathrm{Nb}$ nanolayered composites. Applied Physics Letters, 2008. 92(23): p. 231901.

18. Mara, N.A., Bhattacharyya, D., Hoagland, R.G., and Misra, A., Tensile behavior of $40 \mathrm{~nm} \mathrm{Cu} / \mathrm{Nb}$ nanoscale multilayers. Scripta Materialia, 2008. 58(10): p. 874877.

19. Beyerlein, I.J., et al., Radiation damage tolerant nanomaterials. Materials Today, 2013. 16(11): p. 443.

20. Beyerlein, I.J., et al., Interface-driven microstructure development and ultra high strength of bulk nanostructured $\mathrm{Cu} / \mathrm{Nb}$ multilayers fabricated by severe plastic deformation. Journal of Materials Research, 2013. 28(13): p. 1799-1812.

21. Carpenter, J.S., et al., The Suppression of Instabilities via Biphase Interfaces During Bulk Fabrication of Nanograined Zr. Materials Research Letters, 2014: p. $1-8$.

22. Yasuna, K., Terauchi, M., Otsuki, A., Ishihara, K.N., and Shingu, P.H., Formation of nanoscale $\mathrm{Fe} / \mathrm{Ag}$ multilayer by repeated press-rolling and its layer thickness dependence of magnetoresistance. Materials Science and Engineering A, 2000. 285(1-2): p. 412-417. 
23. Nizolek, T., et al., Processing and Deformation Behavior of Bulk $\mathrm{Cu}-\mathrm{Nb}$

Nanolaminates. Metallography, Microstructure, and Analysis, 2014. 3(6): p. 470476.

24. Knezevic, M., et al., Texture evolution in two-phase $\mathrm{Zr} / \mathrm{Nb}$ lamellar composites during accumulative roll bonding. International Journal of Plasticity, 2014. 57: p. 16-28.

25. Mara, N. and Beyerlein, I., Review: effect of bimetal interface structure on the mechanical behavior of $\mathrm{Cu}-\mathrm{Nb}$ fcc-bcc nanolayered composites. Journal of Materials Science, 2014. 49(19): p. 6497-6516.

26. Ghalandari, L. and Moshksar, M.M., High-strength and high-conductive Cu/Ag multilayer produced by ARB. Journal of Alloys and Compounds, 2010. 506(1): p. 172-178.

27. Min, G., Lee, J.M., Kang, S.B., and Kim, H.W., Evolution of microstructure for multilayered $\mathrm{Al} / \mathrm{Ni}$ composites by accumulative roll bonding process. Materials Letters, 2006. 60(27): p. 3255-3259.

28. Nizolek, T., Metallography of a modern pattern-welded steel knife blade. Advanced Materials and Processes, 2009. 167(2): p. 24-25.

29. Reibold, M., et al., Materials: Carbon nanotubes in an ancient Damascus sabre. Nature, 2006. 444(7117): p. 286.

30. Beyerlein, I.J., et al., Interface-driven microstructure development and ultra high strength of bulk nanostructured $\mathrm{Cu}-\mathrm{Nb}$ multilayers fabricated by severe plastic deformation. Journal of Materials Research, 2013. 28(13): p. 1799-1812.

31. Beyerlein, I.J., et al., Influence of slip and twinning on the crystallographic stability of bimetal interfaces in nanocomposites under deformation. Acta Materialia, 2014. 72: p. 137-147.

32. Carpenter, J.S., et al., Thermal stability of $\mathrm{Cu}-\mathrm{Nb}$ nanolamellar composites fabricated via accumulative roll bonding. Philosophical Magazine, 2013. 93(7): p. 718-735.

33. Zheng, S., Carpenter, J.S., McCabe, R.J., Beyerlein, I.J., and Mara, N.A., Engineering Interface Structures and Thermal Stabilities via SPD Processing in Bulk Nanostructured Metals. Scientific Reports, 2014. 4: p. 4226.

34. Nizolek, T., Mara, N.A., Beyerlein, I.J., Avallone, J.T., and Pollock, T.M., Enhanced Plasticity via Kinking in Cubic Metallic Nanolaminates. Advanced Engineering Materials, 2014. in press. DOI: 10.1002/adem.201400324.

35. Carpenter, J.S., McCabe, R.J., Beyerlein, I.J., Wynn, T.A., and Mara, N.A., A wedge-mounting technique for nanoscale electron backscatter diffraction. Journal of Applied Physics, 2013. 113(9).

36. Lee, S.B., LeDonne, J.E., Lim, S.C.V., Beyerlein, I.J., and Rollett, A.D., The heterophase interface character distribution of physical vapor-deposited and accumulative roll-bonded $\mathrm{Cu}-\mathrm{Nb}$ multilayer composites. Acta Materialia, 2012. 60(4): p. 1747-1761.

37. Toth, L.S., Molinari, A., and Raabe, D., Modeling of rolling texture development in a ferritic chromium steel. Metallurgical and Materials Transactions A, 1997. 28(11): p. 2343-2351. 
38. Jiang, L., et al., Texture, microstructure and mechanical properties of equiaxed ultrafine-grained $\mathrm{Zr}$ fabricated by accumulative roll bonding. Acta Materialia, 2008. 56(6): p. 1228-1242.

39. Khan, A.S., Pandey, A., Gnäupel-Herold, T., and Mishra, R.K., Mechanical response and texture evolution of AZ31 alloy at large strains for different strain rates and temperatures. International Journal of Plasticity, 2011. 27(5): p. 688706.

40. Eftink, B.P., et al., Anomalous deformation twinning in coarse-grained $\mathrm{Cu}$ in Ag60Cu40 composites under high strain-rate compressive loading. Materials Science \& Engineering A, 2014. 618: p. 254-261.

41. Kacher, J., Eftink, J., Cui, J., and Robertson, J., Dislocation interactions with grain boundaries. Current Opinion in Solid State and Materials Science, 2014. 18(4): p. 227-243.

42. Kingstedt, O.T., Eftink, B., Lambros, J., and Robertson, I.M., Quasi-static and dynamic compressive deformation of a bulk nanolayered $\mathrm{Ag}-\mathrm{Cu}$ eutectic alloy: Macroscopic response and dominant deformation mechanisms. Materials Science \& Engineering A, 2014. 595: p. 54.

43. Embury, J.D. and Han, K., Conductor materials for high field magnets. Current Opinion in Solid State and Materials Science, 1998. 3(3): p. 304-308.

44. Lecouturier, F., Spencer, K., Embury, L., and Thilly, J.D., Perspectives for Cu/SS macrocomposite and $\mathrm{Cu} / \mathrm{X}$ nanofilamentary conductors used in non-destructive high-field pulsed magnets under cryogenic conditions, 2004. p. 582-588.

45. Zhou, D.S. and Shiflet, G.J., Ferrite: Cementite crystallography in pearlite. Metallurgical Transactions A, 1992. 23(4): p. 1259-1269.

46. Hirsch, J. and Lücke, K., Overview no. 76. Mechanism of deformation and development of rolling textures in polycrystalline f.c.c. metals-I. Description of rolling texture development in homogeneous $\mathrm{CuZn}$ alloys. Acta Metallurgica, 1988. 36(11): p. 2863-2882.

47. Carpenter, J.S., et al., Processing parameter influence on texture and microstructural evolution in $\mathrm{Cu}-\mathrm{Nb}$ multilayer composites fabricated via Accumulative Roll Bonding. Metallurgical and Materials Transactions A, 2014. 45(4): p. 2192-2208.

48. Heringhaus, F., Raabe, D., and Gottstein, G., On the correlation of microstructure and electromagnetic properties of heavily cold worked $\mathrm{Cu}-20 \mathrm{wt} \% \mathrm{Nb}$ wires. Acta Metallurgica Et Materialia, 1995. 43(4): p. 1467-1476.

49. Raabe, D., Ball, J., and Gottstein, G., Rolling textures of a $\mathrm{Cu} / 20 \% \mathrm{Nb}$ composite. Scripta Metallurgica et Materiala, 1992. 27(2): p. 211-216.

50. Heringhaus, F., Raabe, D., Hangen, U., and Gottstein, G., Textures of Rolled and Wire Drawn Cu-20\%Nb. Materials Science Forum, 1994. 157-162: p. 709-714.

51. Raabe, D., Heringhaus, F., Hangen, U., and Gottstein, G., Investigation of a Cu20 Mass-Percent Nb In-Situ Composite: 1.) Fabrication, Microstructure, and Mechanical Properties. Zeitschrift Fur Metallkunde, 1995. 86(6): p. 405-415.

52. Carpenter, J.S., et al., Bulk texture evolution of $\mathrm{Cu}-\mathrm{Nb}$ nanolamellar composites during accumulative roll bonding. Acta Materialia, 2012. 60(4): p. 1576-1586.

53. Sandim, H. and Raabe, D., EBSD study of grain subdivision of a Goss grain in coarse-grained cold-rolled niobium. Scripta Materialia, 2005. 53(2): p. 207-212. 
54. Sandim, H.R.Z., Bernardi, H.H., Verlinden, B., and Raabe, D., Equal channel angular extrusion of niobium single crystals. Materials Science and Engineering A, 2007. 467(1-2): p. 44-52.

55. Jia, N., Roters, F., Eisenlohr, P., Raabe, D., and Zhao, X., Simulation of shear banding in heterophase co-deformation: Example of plane strain compressed $\mathrm{Cu}$ $\mathrm{Ag}$ and $\mathrm{Cu}-\mathrm{Nb}$ metal matrix composites. Acta Materialia, 2013. 61(12): p. 45914606.

56. Misra, A. and Hoagland, R.G., Effects of elevated temperature annealing on the structure and hardness of copper/niobium nanolayered films. Journal of Materials Research, 2005. 20(8): p. 2046-54.

57. Herrera, C., Ponge, D., and Raabe, D., Design of a novel Mn-based 1 GPa duplex stainless TRIP steel with $60 \%$ ductility by a reduction of austenite stability. Acta Materialia, 2011. 59(11): p. 4653-4664.

58. Chen, J.K., Chen, G., and Reynolds, W.T., Interfacial structure and growth mechanisms of lath-shaped precipitates in Ni-45 wt\% Cr. Philosophical Magazine A, 1998. 78(2): p. 405-422.

59. Demkowicz, M.J. and Thilly, L., Structure, shear resistance and interaction with point defects of interfaces in $\mathrm{Cu}-\mathrm{Nb}$ nanocomposites synthesized by severe plastic deformation. Acta Materialia, 2011. 59(20): p. 7744-56.

60. Sauvage, $\mathrm{X}$., et al., Solid state amorphization in cold drawn $\mathrm{Cu} / \mathrm{Nb}$ wires. Acta Materialia, 2001. 49(3): p. 389-394.

61. Carpenter, J.S., et al., A comparison of texture results obtained using precession electron diffraction and neutron diffraction methods at diminishing length scales in ordered bimetallic nanolamellar composites. Scripta Materialia, 2012. 67(4): p. 336-339.

62. Ekiz, E.H., et al., Microstructural evolution of nanolayered $\mathrm{Cu}-\mathrm{Nb}$ composites subjected to high-pressure torsion. Acta Materialia, 2014. 72: p. 178-191.

63. Yu-Zhang, K., Embury, J.D., Han, K., and Misra, A., Transmission electron microscopy investigation of the atomic structure of interfaces in nanoscale $\mathrm{Cu}-\mathrm{Nb}$ multilayers. Philosophical Magazine, 2008. 88(17): p. 2559-2567.

64. Huang, X., et al., Evolution of microstructural morphology and boundary spacing during high pressure torsion of nickel, in Ultrafine Grained Materials III, Zhu, Y.T., et al., Editors. 2004. p. 235-240.

65. Xue, Q., Alexander, I.J., Gray Iii, D.J., and Beyerlein, G.T., Mechanisms for initial grain refinement in OFHC copper during equal channel angular pressing. Acta Materialia, 2007. 55(2): p. 655-668.

66. Carpenter, J.S., Mccabe, R.J., Mayeur, J.R., Mara, N.A., and Beyerlein, I.J., Interface-driven plasticity: The presence of an Interface Affected Zone in metallic lamellar composites. Advanced Engineering Materials, 2014. in press. DOI:10/1002/adem.201400210.

67. Kang, K., Wang, J., and Beyerlein, I.J., Atomic structure variations of mechanically stable fcc-bcc interfaces. Journal of Applied Physics, 2012. 111(5): p. 053531.

68. Wang, J., et al., Structure and Property of Interfaces in ARB $\mathrm{Cu} / \mathrm{Nb}$ Laminated Composites. Jom, 2012. 64(10): p. 1208-1217. 
69. Kang, K., Wang, J., Zheng, S.J., and Beyerlein, I.J., Minimum energy structures of faceted, incoherent interfaces. Journal of Applied Physics, 2012. 112(7): p. 073501 (10 pp.).

70. Wang, J., Zhang, R.F., Zhou, C.Z., Beyerlein, I.J., and Misra, A., Interface dislocation patterns and dislocation nucleation in face-centered-cubic and bodycentered-cubic bicrystal interfaces. International Journal of Plasticity, 2014. 53: p. 40.

71. Beyerlein, I.J., et al., Emergence of stable interfaces under extreme plastic deformation. Proceedings of the National Academy of Sciences of the United States of America, 2014. 111(12): p. 4386-4390.

72. Mayeur, J.R., Beyerlein, I.J., Bronkhorst, C.A., Mourad, H.M., and Hansen, B.L., A crystal plasticity study of heterophase interface character stability of $\mathrm{Cu} / \mathrm{Nb}$ bicrystals. International Journal of Plasticity, 2013. 48: p. 72.

73. Zheng, S., et al., High-strength and thermally stable bulk nanolayered composites due to twin-induced interfaces. Nature Communications, 2013. 4.

74. McCabe, R.J., Beyerlein, I.J., Carpenter, J.S., and Mara, N.A., The critical role of grain orientation and applied stress in nanoscale twinning. Nature Communications, 2014. 5.

75. Zhu, Y.T., Liao, X.Z., and Wu, X.L., Deformation twinning in nanocrystalline materials, in Prog. Mater. Sci.2012. p. 1-62.

76. Beyerlein, I.J., Zhang, X., and Misra, A., Growth Twins and Deformation Twins in Metals, in Annu. Rev. Mater. Res.2014. p. 329-363.

77. Hunter, A. and Beyerlein, I.J., Unprecedented grain size effect on stacking fault width. APL Materials, 2013. 1(3): p. 032109.

78. Hunter, A. and Beyerlein, I.J., Predictions of an alternative pathway for grainboundary driven twinning. Applied Physics Letters, 2014. 104(23).

79. Beyerlein, I.J., Wang, J., Kang, K., Zheng, S.J., and Mara, N.A., Twinnability of bimetal interfaces in nanostructured composites. Materials Research Letters, 2013. 1(2): p. 89-95.

80. Anderoglu, O., Misra, A., Wang, H., and Zhang, X., Thermal stability of sputtered $\mathrm{Cu}$ films with nanoscale growth twins. Journal of Applied Physics, 2008. 103: p. 094322.

81. Kobiyama, M., Inami, T., and Okuda, S., Mechanical behavior and thermal stability of nanocrystalline copper film prepared by gas deposition method. Scripta Materialia, 2001. 44(8-9): p. 1547-1551.

82. Bellou, A., Bahr, L., and Scudiero, D.F., Thermal stability and strength of Mo/Pt multilayered films. Journal of Materials Science, 2010. 45(2): p. 354-362.

83. Misra, A. and Hoagland, R.G., Thermo-mechanical stability of metallic nanolaminates. Jom, 2004. 56(11): p. 140-141.

84. Misra, A., Hoagland, R.G., and Kung, H., Thermal stability of self-supported nanolayered $\mathrm{Cu} / \mathrm{Nb}$ films. Philosophical Magazine, 2004. 84(10): p. 1021-8.

85. Zheng, S., Carpenter, J.S., Wang, J., Mara, N.A., and Beyerlein, I.J., An interface facet driven Rayleigh instability in high-aspect-ratio bimetallic nanolayered composites. Applied Physics Letters, 2014. 105(11).

86. Josell, D. and Spaepen, F., Surfaces, interfaces, and changing shapes in multilayered films. MRS Bulletin, 1999. 24(2): p. 39-43. 
87. Lewis, A.C., Josell, D., and Weihs, T.P., Stability in thin film multilayers and microlaminates: the role of free energy, structure, and orientation at interfaces and grain boundaries. Scripta Materialia, 2003. 48(8): p. 1079-85.

88. Werner, E. and Prantl, W., Slip transfer across grain and phase boundaries. Acta Metallurgica Et Materialia, 1990. 38(3): p. 533-537.

89. Odette, G.R., Alinger, M.J., and Wirth, B.D., Recent developments in irradiationresistant steels, in Ann. Rev. Mater. Res.2008. p. 471-503.

90. Odette, G.R. and Hoelzer, D.T., Irradiation-tolerant nanostructured ferritic alloys: Transforming helium from a liability to an asset. JOM, 2010. 62(9): p. 84-92.

91. Mara, N.A., et al., High-temperature mechanical behavior/microstructure correlation of $\mathrm{Cu} / \mathrm{Nb}$ nanoscale multilayers. Materials Science and Engineering A, 2008. 493(1-2): p. 274-282.

92. Mara, N.A., et al., The effects of decreasing layer thickness on the high temperature mechanical behavior of $\mathrm{Cu} / \mathrm{Nb}$ nanoscale multilayers. Thin Solid Films, 2007. 515(6): p. 3241-3245.

93. Cobb, J., et al., Layer Stability and Material Properties of Friction-Stir Welded $\mathrm{Cu}-\mathrm{Nb}$ Nanolamellar Composite Plates. Materials Research Letters, 2014. 2(4): p. 227-232.

94. Hirth, J.P., Influence of grain boundaries on mechanical properties. Metall Trans, 1972. 3(12): p. 3047-3067.

95. Zhang, R.F., Germann, T.C., Wang, J., Liu, X.Y., and Beyerlein, I.J., Role of interface structure on the plastic response of $\mathrm{Cu} / \mathrm{Nb}$ nanolaminates under shock compression: Non-equilibrium molecular dynamics simulations. Scripta Materialia, 2012. 68(114).

96. Mayeur, J.R., Beyerlein, I.J., Bronkhorst, C.A., and Mourad, H.M., Incorporating interface affected zones into crystal plasticity. International Journal of Plasticity, 2015. 65: p. 206-225. 